\title{
Study of low-dose creatine supplementation for endogenous creatine synthesis during heavy-load exercise
}

\author{
X. $\mathrm{Li}^{1}$, M. Xiang ${ }^{2}$, L. S. Harbige ${ }^{2}$, P. X. Meng ${ }^{1}$ and H. $\mathrm{Ai}^{1}$ \\ ${ }^{1}$ Division of Nutrition and Biochemistry, Institute of Sports Medicine, The Third Hospital, Peking University, Beijing, \\ P.R. China and ${ }^{2}$ Centre for Biosciences Research, School of Science, University of Greenwich, Kent ME4 4TB, UK
}

\begin{abstract}
Creatine (Cre) supplementation is an athletic aid used to increase high-intensity athletic performance ${ }^{(1)}$. Although the use of Cre has been known as an energy source by skeletal muscles since the beginning of the 20th century, Cre was popularised as a performance-enhancing supplementation in $1992^{(2)}$. In humans, Cre is recommended to be taken orally as a loading dose of $20 \mathrm{~g} / \mathrm{d}(0.3 \mathrm{~g} / \mathrm{kg} / \mathrm{d}, 67 \mathrm{~kg}$ body weight) for 5-7 days, followed by a long-term maintenance dose of $2-5 \mathrm{~g} / \mathrm{d}(0.03-0.075 \mathrm{~g} / \mathrm{kg} / \mathrm{d})$. In rats, the doses of $1.5 \mathrm{~g} / \mathrm{kg} / \mathrm{d} \mathrm{and} 0.15 \mathrm{~g} / \mathrm{kg} / \mathrm{d}$ were calculated from the recommended loading dose of $20 \mathrm{~g} / \mathrm{d}(0.3 \mathrm{~g} / \mathrm{kg} / \mathrm{d})$ and the maintainable dose of $2 \mathrm{~g} / \mathrm{d}(0.03 \mathrm{~g} / \mathrm{kg} / \mathrm{d})$ for human subjects according to Calabrese ${ }^{(3)}$. Thus the amounts of $0.0375-0.30 \mathrm{~g} / \mathrm{kg} / \mathrm{d}$ Cre were considered to be low dose in the rat study. L-arginine:glycine amidinotransferase (L-AGAT) in the kidney is the rate-limiting enzyme of endogenous Cre synthesis in mammals, and the guanidinoacetic acid (GAA) is the precursor in this synthesis. The present study has investigated the effect of supplementation with 0 , $0.0375,0.075,0.15$ and $0.30 \mathrm{~g} \mathrm{Cre} / \mathrm{kg}$ body weight per day for 4 weeks on the L-AGAT activity in the kidneys, the GAA concentration in the liver, and serum Cre and creatinine in swim-trained male Sprague-Dawley rats. L-AGAT and GAA were determined spectroscopically. Cre and creatinine in serum were also measured using an autoanalyser (7170A Hitachi). Treatment groups rats $(n=10$ per group) were trained to swim for $4 \mathrm{~h} / \mathrm{d}$ and 6 days/week for 4 weeks. The control group rats (without Cre supplementation, $n=10$ ) were sedentary for 4 weeks. In the comparison between the swim-trained group without Cre supplementation and the control group, L-AGAT activity and GAA concentration in the swim-trained group increased (\%) by 20.8 and 10.6, which is in agreement with our 'high-dose' study. In five swim-trained groups, the L-AGAT activity and the GAA concentration decreased (\%) by 15.8, 30.0, 32.8 and 38.4\%, and $6.8,11.9,13.9$ and $24.6 \%$, respectively, in the groups supplemented with $0.0375,0.075,0.15$ and $0.30 \mathrm{~g}$ Cre/kg body weight per day for 4 weeks compared with the group without Cre supplementation. No significant differences were found in the serum Cre and creatinine concentrations among the six groups. These results indicate that for rats L-AGAT activity and GAA concentration could be markedly enhanced by heavy-load exercise, implying that heavy-load exercise may benefit endogenous Cre synthesis due to increased Cre need during exercise. The L-AGAT activity and GAA concentration could be reduced by supplementation with $0.075-0.30 \mathrm{~g}$ Cre/kg per day; however, there were no significant differences in the serum Cre and creatinine concentrations among the six groups, suggesting that rats supplementation with low-dose Cre $(0.0375-0.30 \mathrm{~g}$ Cre/kg per day) may meet the Cre needed during heavy-load exercise, therefore, it is unnecessary to enhance the Cre dose in order to avoid the depression of endogenous Cre metabolism. These results may be relevant to the immune system and this aspect is currently being investigated in lymphocytes, as little is known about the effect of Cre supplementation on immune cells.
\end{abstract}

1. Johnston AP, Burke DG, MacNeil LG et al. (2009) J Strength Cond Res 23, 116-120.

2. Bemben MG \& Lamont HS (2005) Sports Med 35, 107-125.

3. Calabrese EJ (1991) Principles of Animal Extrapolation, pp. 499-527. Chelsea, MI: Lewis Publishers Inc. 